\section{Linhas de tensões no processo de acolhimento das equipes de saúde bucal do Programa Saúde da Família: o caso de Alagoinhas, Bahia, Brasil}

\author{
Conflicting situations in the reception of oral \\ health teams from the Family Health Program \\ in Alagoinhas, Bahia, Brazil
}

Adriano Maia dos Santos 1

Marluce Maria Araújo Assis 1

Ana Áurea Alécio de Oliveira Rodrigues 1,2

Maria Angela Alves do Nascimento 1

Maria Salete Bessa Jorge 3

\footnotetext{
1 Núcleo de Pesquisa Integrada em Saúde Coletiva Docentes, Universidade Estadual de Feira de Santana,

Feira de Santana, Brasil. 2 Universidade Estadual do Sudoeste da Bahia, Jequié, Brasil.

3 Programa de Pós-graduação em Saúde Pública, Universidade Estadual do Ceará,

Fortaleza, Brasil.

Correspondência M. M. A. Assis

Núcleo de Pesquisa Integrada em Saúde Coletiva Docentes, Universidade Estadual de Feira de Santana. Rua C 121, Conjunto A.C.M., Feira de Santana BA 44036-000, Brasil. marluceassis@bol.com.br nupisc@uefs.br
}

\begin{abstract}
The study discusses the conflicting situations that arise while receiving oral health teams in Alagoinhas, Bahia, Brazil. The main orientation for the Family Health Program is based on analyzing health care work flowcharts. The current qualitative research used semi-structured interviews and practical observation as the data collection techniques. There were 17 study subjects: group I (dentists and dental assistants - 6); group II (other health workers - 6); and group III (users - 5). Users' first contact with the family health team is in the reception, often in a tense and conflicting atmosphere, but with the potential for alternatives for change, as a privileged space for the use of low-key technologies. The therapeutic process varies: e.g. clinical consultation, emergency care, scheduled follow-up, and referral to other health services in the system. However, oral health teams conduct the reception process in different ways, depending on the practitioners' commitment and unique characteristics.
\end{abstract}

Oral Health; Health Services Accessibility; Health Services Evaluation

\section{Introdução}

O Sistema Único de Saúde (SUS) materializou, em seus princípios e diretrizes, o ideário da Reforma Sanitária, ao assumir a saúde como direito fundamental do ser humano e estabelecer a responsabilidade do Estado em prover e garantir a saúde, por meio de políticas econômicas e sociais integrativas. Cecílio ${ }^{1}$ faz uma (re)interpretação do ideário da Reforma Sanitária, com base na universalidade, integralidade e eqüidade, considerados os conceitos-signos do pensamento sócio-político da saúde pública. Todavia, a luta pela consolidação desses conceitos-signos implica, essencialmente, a construção de práticas inovadoras em saúde, a partir da gestão, do planejamento e do processo de trabalho organizado pelas necessidades reais dos usuários do serviço.

Nessa direção, o presente estudo recorta o dispositivo acolhimento como uma possibilidade de construir uma nova prática em saúde, compreendendo-o como ações comunicacionais, atos de receber e ouvir a população que procura os serviços de saúde, dando respostas adequadas a cada demanda em todo o percurso da busca; desde a recepção e o atendimento individual ou coletivo, até o encaminhamento externo, retorno, remarcação e alta.

Dispositivo ou agenciamento 2 (p. 218) é a expressão de um "sistema semiótico, um regime de signos, e o conteúdo de um sistema pragmático, ações e paixões". Portanto, é delimitado em di- 
ferentes linhas que podem ser potencialidades criadoras, conservadoras ou destrutivas. Linhas tênues e dinâmicas que carreiam os territórios individuais e coletivos de conteúdo e expressão. No campo específico dos territórios que engendram as práticas de saúde (individuais e coletivas), o agenciamento poderia manter, ameaçar, destruir ou transformar os espaços de intervenção das referidas práticas. Nesse sentido, uma das possibilidades para edificar novas formas de se fazer saúde, seria a potencialização do dispositivo acolhimento, articulado ao estabelecimento de vínculo entre usuários, trabalhadores de saúde e gestores do sistema de saúde, em busca da humanização do atendimento. A unidade de saúde passaria a organizar sua demanda, de acordo com as necessidades e prioridades e, não somente, por meio da ordem de chegada; evitando, na medida do possível, filas desnecessárias e perda de tempo ${ }^{3,4}$.

Tais observações são compartilhadas por Merhy 5, quando discorre sobre a lógica do acolhimento em serviços de saúde, ao considerá-lo como um espaço de encontro entre trabalhador/ usuário que se abre para um processo de escuta dos problemas, não só para troca de informações e mútuo reconhecimento de direitos e deveres, como também para um processo de decisões que pode possibilitar intervenções pertinentes e/ou eficazes, em torno das necessidades dos usuários. A acolhida prevê a oferta de serviços às necessidades demandadas, bem como a responsabilização integral pelos problemas de saúde de uma coletividade, por meio das tecnologias disponíveis.

Mendes-Gonçalves 6, ao discutir as relações que ocorrem no processo de trabalho das equipes de saúde, considera que a tecnologia é um conjunto de saberes e instrumentos que expressa nos processos de produção dos serviços a rede de relações sociais entre agentes e práticas, conformada em uma totalidade social, que é constituída não apenas pelo saber, mas também pelos seus desdobramentos materiais e não-materiais.

Merhy 7 complementa tal afirmação, classificando as tecnologias envolvidas no trabalho em saúde em três tipos: leve, considerada a tecnologia de relação do tipo produção de vínculo, acolhimento e gestão, estabelecida nos encontros entre os diferentes componentes da equipe de saúde; leve-dura, aquela dos saberes estruturados que operam no processo de trabalho em saúde, como a clínica médica e a epidemiologia; e dura, operada por equipamentos tecnológicos do tipo máquina, normas, estruturas organizacionais e outros.

Assim, tomar o acolhimento como objeto das práticas implica relacioná-lo aos modelos de atenção à saúde, que investem na qualidade dos serviços, tendo a responsabilização como produto e produtor de dispositivos, afinal, quem co-participa ativamente dos problemas de saúde das pessoas, ouvindo e conversando, estabelece cotas de responsabilidade em sentido duplo, cuida - faz clínica - e, inexoravelmente, estabelece acolhimento e vice-versa 8 .

Para superar o modelo de saúde centrado na doença e em práticas curativas, o Ministério da Saúde 9 lança, em 1994, o Programa Saúde da Família (PSF), objetivando a reorganização do processo de trabalho em saúde na atenção básica, vislumbrando a incorporação de novos conceitos e práticas inovadoras, balizadas por diferentes tecnologias necessárias para responder às necessidades apresentadas nos espaços concretos, onde as pessoas constroem suas histórias e representam seu processo de saúde-doença. Para tanto, sinalizou uma mudança no foco da atenção, que passa a ser a família assistida no seu espaço social - área adscrita - com suas singularidades. O programa propõe, ainda, um redirecionamento no processo de trabalho, baseado na interação com uma equipe multiprofissional, visando às práticas mais resolutivas e integrais, dentro da perspectiva da vigilância à saúde, esta concebida para a recondução da lógica assistencial, a qual deve superar as intervenções voltadas para a cura individual, orientando, para tanto, o uso da epidemiologia, como eixo estruturante das ações coletivas.

A saúde bucal passou a fazer parte do PSF em 28 de dezembro de 2000, quando foi sancionada a Portaria $n .1 .444$ 10, na qual o Ministério da Saúde estabelece incentivo financeiro para a reorganização da atenção em saúde bucal. O Artigo 2o, dessa Portaria, destaca que "o trabalho das equipes de saúde bucal, no PSF, estará voltado para a reorganização de acesso às ações de saúde, garantindo-se a atenção integral aos indivíduos e às famílias, mediante o estabelecimento do vínculo territorial" 10 (p. 85).

A Portaria n. 267 11, de 6 de março de 2001, regulamentou a Portaria n. 1.44410 e descreveu as bases para reorganização das ações de saúde bucal na atenção básica: caráter substitutivo das práticas tradicionais exercidas nas unidades básicas de saúde; adscrição da população sob a responsabilidade da unidade básica de saúde; integralidade da assistência prestada à população adscrita; articulação com os serviços de maior complexidade do sistema de saúde; definição da família como núcleo central de abordagem; humanização do atendimento; abordagem multiprofissional; estímulo às ações de promoção da saúde, à articulação intersetorial, à participação e ao controle social; educação permanente dos 
profissionais; acompanhamento e avaliação permanente das ações realizadas.

No entanto, diferente dos outros trabalhadores de saúde, que, no PSF, trabalham em uma área de adscrição específica, a equipe de saúde bucal deve exercer suas atividades em duas equipes distintas, ou seja, para cada equipe de saúde bucal serão implantadas duas equipes de saúde da família 10.

A Portaria n. 673 12, de 3 de junho de 2003, estabelece que o número das equipes de saúde bucal implantadas pode ser o mesmo das equipes de PSF, porém não inclui o dentista na equipe mínima do programa. Logo, a inserção ou não desse profissional passa a ser responsabilidade dos gestores municipais, inclusive a questão da proporcionalidade entre as equipes de PSF e as de saúde bucal.

Contudo, desde a inserção da saúde bucal no PSF, tem havido uma expansão no número de equipes em todo o país, sendo que, em 2004, foram implantadas 7.131 equipes que atendiam cerca de 39 milhões de pessoas 13. Porém, ainda que se questione a prática exercida e a relação entre o número de equipes de saúde bucal e do PSF, é possível reconhecer que a expansão tem resultado em maior acesso da população aos serviços de saúde bucal.

Diante do exposto, identificam-se algumas questões que orientaram o desenvolvimento desta pesquisa: as relações estabelecidas entre os sujeitos sociais (equipes de saúde bucal e usuários), no PSF, proporcionam acolhimento? Quais são as linhas de tensões nos momentos de encontro entre equipes de saúde bucal e usuários do PSF?

Com base nessas considerações, estabeleceu-se o seguinte objetivo: analisar as relações estabelecidas entre a equipe de saúde bucal e os usuários do PSF, no que se refere ao processo de acolhimento dos usuários, tomando, como eixo orientador, os fluxogramas analisadores do processo de trabalho em saúde propostos por Merhy 5,7.

\section{Metodologia}

Trata-se de uma pesquisa de abordagem qualitativa, que procura compreender uma realidade específica, de forma abrangente e profunda em suas múltiplas dimensões 14 . O estudo foi realizado em três unidades de saúde da família em que atuavam as equipes de saúde bucal da Secretaria Municipal de Saúde de Alagoinhas, Bahia, Brasil. O município encontra-se na Gestão Plena do Sistema Municipal, respondendo pela atenção básica e pelos serviços de média e alta complexi- dades da rede local de saúde. Na atenção básica funcionam duas estratégias de reorganização, o Programa de Agentes Comunitários de Saúde (PACS) e o PSF, sendo este implantado em 199815. Até agosto de 2005, no município havia 21 equipes de saúde da família responsáveis, aproximadamente, por $52 \%$ de cobertura da população. As equipes de saúde bucal foram implantadas em 2001, contando atualmente com 12 equipes.

As técnicas de coleta de dados foram: a entrevista semi-estruturada e a observação sistemática da prática (48 horas). Os sujeitos entrevistados foram 17 pessoas que atuaram no PSF ou foram atendidas pela equipe de saúde bucal, no período de 2001-2004, distribuídas entre três grupos de representação: grupo I (4 cirurgiõesdentistas e 2 auxiliares de consultório dentário = 6 pessoas); grupo II ( 2 enfermeiros, 3 agentes comunitários de saúde e 1 agente administrativo = 6 pessoas) e grupo III (usuários do sistema $=$ 5 pessoas). O critério numérico não foi o responsável para se estabelecer a amostragem do estudo 14, mas o conjunto de informações dos diferentes sujeitos sobre o fenômeno em estudo, para possibilitar apontar as semelhanças e diferenças das práticas de saúde bucal avaliadas no processo de acolhimento em unidades de saúde da família, nos momentos das observações e reveladas pelos sujeitos pesquisados. A definição do número de entrevistados e observações realizadas foi orientada pela reincidência das informações, porém não foram desprezadas informações ímpares, cujo potencial explicativo serviu de baliza para as análises do objeto em estudo.

As referidas técnicas de coleta de dados foram orientadas por roteiro, constando informações acerca do participante do estudo, em torno das linhas de tensões nos momentos de encontro do processo de acolhimento, por meio dos seguintes pontos: (1) porta de entrada da unidade de saúde da família (quem e como); (2) relacionamento entre equipe e usuário; (3) oferta - tipo de demanda (organizada, espontânea), número de vagas; (4) sistema de atendimento (consultas agendadas, critérios de marcação de consultas); e (5) encaminhamentos para outros serviços. A coleta de dados aconteceu no período de fevereiro a julho de 2004. As entrevistas foram gravadas, transcritas e conferidas com a gravação oral. As observações foram registradas em um diário de campo.

A análise dos dados foi orientada pelo fluxograma analisador proposto por Merhy 5,7. Tratase de uma representação gráfica do processo de trabalho em unidades de saúde, elaborado de forma centrada no usuário. O autor propõe uma análise das interfaces entre os sujeitos da prática, seus métodos de ação e modo como interagem, possibilitando uma nova compreensão sobre as 
práticas em saúde, que é, essencialmente, um tipo de força que opera em ação permanente e em relação. Portanto, neste estudo, procurou-se estabelecer interfaces com as linhas de tensões do processo de acolhimento, no momento da prática desenvolvida pela equipe de saúde bucal no PSF.

Nesse sentido, Merhy 5,7 considera que quaisquer serviços assistenciais de saúde podem ser enquadrados na seqüência mostrada pelo diagrama apresentado na Figura 1, que, no presente estudo, será desdobrada nas Figuras 2, 3 e 4, construídas a partir das entrevistas e das observações da prática, com o objetivo de possibilitar uma melhor visualização das informações colhidas por meio da pesquisa empírica.

A entrada é representada, simbolicamente, por uma elipse, caracterizada pelo movimento que, em um dia, se faz na porta de uma unidade de saúde e, no qual, alguns usuários acabam por chegar na etapa da recepção e outros não. A recepção, configurada por um retângulo, constitui-se nas diferentes formas de organização do atendimento na porta de entrada da unidade. A decisão da oferta de serviços é representada por um losango, no qual procura-se registrar os distintos critérios de que os serviços se utilizam para compreender se o que o usuário traz como problema de saúde será ou não objeto de intervenção tecno-assistencial. O cardápio, 2o retângulo, consiste na oferta de determinados serviços pela unidade de saúde, ou seja, tanto as consultas realizadas em um consultório médico ou odontológico, quanto os atendimentos que são realizados no corredor de um modo simples e rápido. Finalmente, os usuários que obtiveram algum tipo de intervenção vão sair ou retornar à unidade, elipse de saída, em várias situações: alta por cura, por óbito ou abandono; encaminhamentos para exames ou para outros serviços assistenciais; e retornos dos mais diferentes tipos do próprio serviço ${ }^{5}$.

Para o presente trabalho, recortam-se as tensões estabelecidas no processo de acolhimento da unidade de saúde, adaptado da Figura 1, e representada no decorrer do caminhar do usuá-

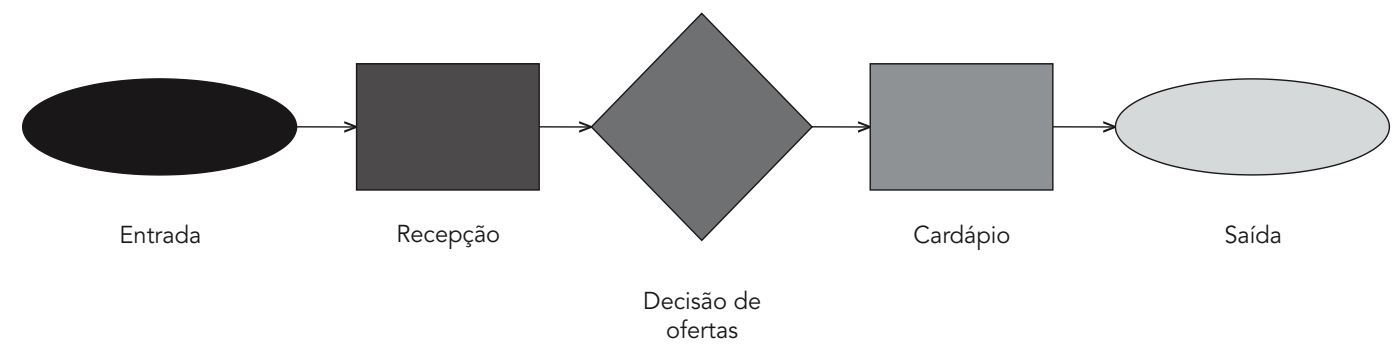

Figura 2

Diagrama da linha de tensão na recepção da unidade de saúde da família.

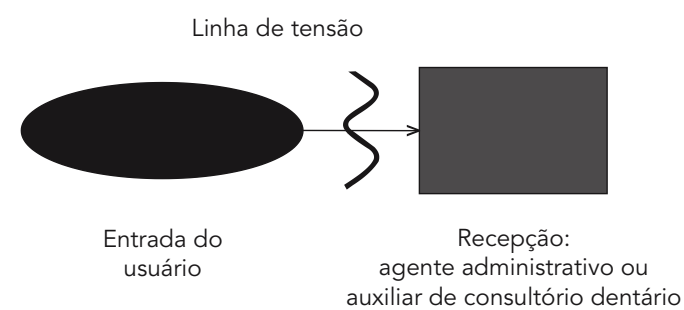

rio nos diversos momentos de atendimento pela equipe de saúde bucal, no PSF de Alagoinhas.

Todos os sujeitos entrevistados receberam um Termo de Consentimento Livre e Esclarecido, constando de esclarecimentos sobre a pesquisa, com solicitação para o fornecimento das informações necessárias e autorização para a participação no estudo. Esse termo está de acordo com a Resolução n. 196/96, do Conselho Nacional de Saúde, que estabelece diretrizes e normas regulamentadoras em pesquisas envolvendo seres humanos 16. O projeto de pesquisa foi submetido e aprovado pelo Comitê de Ética em Pesquisa, da 


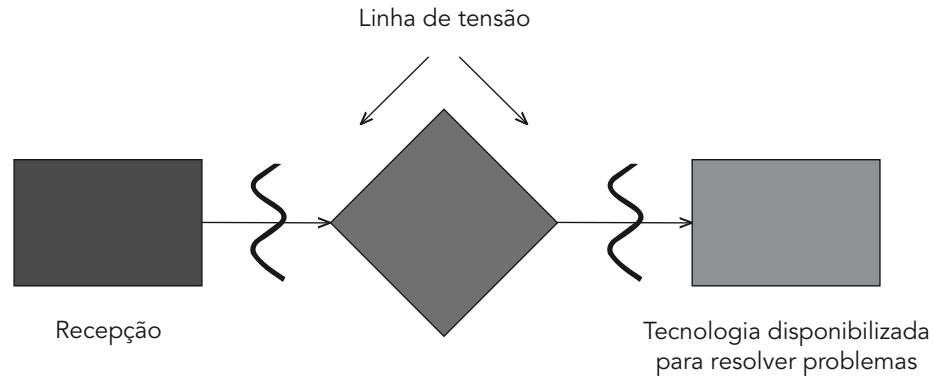

Consultório -

dentista/auxiliar de

consultório dentário/usuário

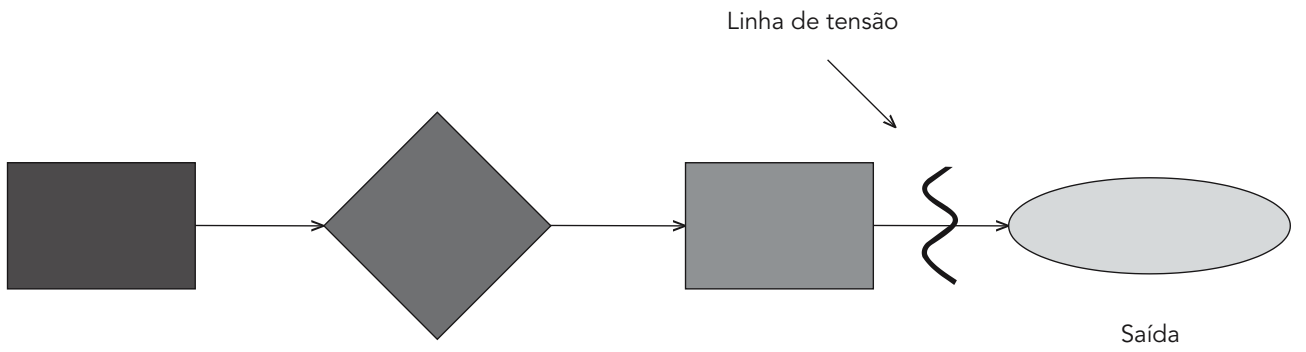

Universidade Estadual de Feira de Santana, que avaliou a pertinência do mesmo, os objetivos da pesquisa e os riscos e/ou benefícios a que estão vulneráveis os participantes da investigação.

\section{Linhas de tensões no processo de acolhimento das equipes de saúde bucal do PSF}

Primeiro momento de encontro: linha de tensão do acolhimento na recepção da unidade de saúde da família

No primeiro momento de encontro, a linha de tensão do acolhimento, na recepção da unidade de saúde da família, é o instante no qual o usuá- rio tem definido quando, com quem e se vai ser atendido. O espaço da recepção funciona como predecessor do processo de relações, contexto privilegiado no processo de acolhimento.

Os depoimentos dos usuários apresentam divergências quanto à satisfação, no instante em que procuram a recepção, representados sob duas perspectivas. A primeira aponta a falta de humanização na porta de entrada, refere que mesmo com uma necessidade urgente, tem seu direito de acesso ao serviço cerceado pelos trabalhadores da recepção, configurando-se como um desencontro entre o usuário e o serviço - um não acolhimento. Os recepcionistas limitam-se a identificar os nomes dos usuários e organizar o atendimento de acordo com o número de vagas: "Quando quero uma informação eu vou até 
a agente administrativa, aí ela me informa como está sendo, dai é que vou entrar no meio desse negócio de esperar ficha, que dia marca e que dia não marca" (Grupo III, entrevistado 14). A segunda diz o oposto: os usuários encontram respostas satisfatórias aos seus problemas quando procuram a unidade de saúde da família, nesse caso, há uma escuta e um retorno às demandas apresentadas: "Aqui no PSF foi muito bom (...) nós somos, assim, muito bem atendidos” (Grupo III, entrevistado 16).

Para Merhy 17 (p. 138), “a função da porta não é mais barrar e limitar o atendimento e, sim, responder aos problemas que ali aparecem de modo criativo, explorando ao máximo as tecnologias leves de que dispomos em nosso saber e em nossas relações".

No entanto, paradoxalmente, as observações mostraram que as recepções, nas unidades de saúde da família estudadas, ainda são burocráticas e conduzidas por critérios administrativos e não técnicos. Os depoimentos convergem com as observações, apontando para o atendimento de uma demanda definida pela oferta restrita na porta de entrada - a recepção. Nessa direção, a forma como se dá o acesso dos usuários à unidade de saúde da família pode conflitar com o princípio da universalidade, considerando que o mesmo é modulado pela ordem de chegada, com cartazes informativos sobre o número de vagas, dias específicos para determinado grupo, presença do trabalhador na unidade, tipo de demanda, triagem ou seleção prévia de alguns casos, dentre outras formas de regular o acesso ao serviço.

$\mathrm{Na}$ realidade, detectaram-se posturas mais relacionais por parte de alguns trabalhadores, como a presença do dentista na recepção, apresentando-se, de forma humanizada e acolhedora, àquele que procura um atendimento de saúde bucal; da mesma forma, uma auxiliar de consultório dentário mostra-se envolvida com os aspectos subjetivos dos usuários que se dirigem à recepção e prioriza algumas necessidades como as urgências, idosos e gestantes: “... a auxiliar de consultório dentário recebe muito bem e procura sempre conversar, sempre olha nos olhos, se o paciente chega com muita dor, ansioso, a auxiliar de consultório dentário verifica a pressão, coloca ele sentado, se for idoso não deixa ele em pé, se for gestante também, então sempre dá um acolhimento..." (Grupo I, entrevistado 4).

Só existe acolhimento quando há diálogo, escuta e envolvimento com a queixa do outro na resolução dos problemas apresentados pelos usuários, sendo imperiosa a co-responsabilização e procura pelo melhor cuidado. Nesse sentido, para Matumoto 18 (p. 89), "uma dispensa pode ser acolhedora, se houver a disposição para escutar, procurar dar o encaminhamento adequado ao caso, percebendo as necessidades do usuário na situação".

A Figura 2 traz a primeira ruptura comunicacional ou o primeiro cuidado terapêutico nas unidades de saúde da família.

O primeiro tensionamento é desencadeado na procura por uma vaga para consulta com o dentista. Esta se desvela no momento da marcação de consultas. O sistema de marcação é baseado na demanda espontânea, por meio de uma procura por consultas odontológicas, uma situação em que não há garantia de que os usuários conseguirão vagas. A limitação no número de consultas impõe uma disputa injusta entre os usuários, que passam a chegar cada vez mais cedo, para garantirem o acesso. Configura-se, assim, como um serviço excludente, conflituoso e tenso, em que o usuário procura alternativas possíveis para ser atendido, porém, se sente muitas vezes inseguro e abandonado na busca cotidiana pelo atendimento ${ }^{19}$. Observou-se que a grande maioria dos que ficam na fila são adolescentes e adultos jovens, enquanto as pessoas que trabalham, idosos, donas-de-casa, acabam por ter dificuldade nesse tipo de organização.

Entretanto, outra modalidade de marcação de consulta é referenciada com o objetivo de acabar com as filas na porta das unidades de saúde com alguns critérios de acesso definidos em reuniões de comunidade, para realização de exames coletivos e organização do atendimento individual: "No primeiro momento tinha muito paciente, tinha briga na fila e isso me causava uma angústia enorme (...) eu resolvi fazer a marcação através da reunião em grupo (...) dali eu levava o nome, fazia triagem de pacientes, então quem tinha mais necessidade, era marcado mais rapidamente" (Grupo I, entrevistado 6).

O processo de acolhimento poderia ser disparador potencial na recondução das práticas. Para tanto, teria de se constituir uma equipe específica para acolher a demanda na porta de entrada dos serviços de saúde, partindo da premissa de que todo usuário tem direito à escuta. Nesse caso, a equipe acolhedora deve ser composta por diferentes trabalhadores dispostos a receber, ouvir e fazer o encaminhamento mais adequado a todos que procuram o serviço de saúde que, por sua vez, deve funcionar de portas abertas $17,20,21$.

Identificaram-se responsabilizações delimitadas aos problemas exclusivos da boca para a equipe de saúde bucal, não estabelecendo interconexões e complementaridades com as práticas desenvolvidas pelos outros trabalhadores que atuam no PSF, constituindo-se em um apêndice ao programa 22 . 
As unidades de saúde da família observadas revelaram uma infra-estrutura deficiente, pois, muitas vezes, estavam em desacordo com as exigências da vigilância sanitária, ou seja, inadequadas para o atendimento às pessoas e ao próprio trabalho do profissional. Detectou-se que as unidades não tinham espaço suficiente para a acomodação dos usuários na recepção, insuficiência de bancos ou cadeiras, sendo que os existentes eram desconfortáveis; ausência de qualquer meio de entretenimento (televisão, som, revistas, jornais) para os usuários durante a espera; aspecto envelhecido ou mesmo sujo das paredes da recepção e dos consultórios; alguns consultórios sem ar condicionado, o que, segundo os trabalhadores, prejudicava o atendimento, o conforto e a segurança; uma das cadeiras odontológicas era antiga, colocando em risco a integridade física das pessoas que transitavam no consultório.

Resumindo, todas essas dificuldades impõem diferentes graus de satisfação aos usuários e trabalhadores, apesar de convergir na forma de receber, ouvir, escutar, falar, tolerar, acolher. Não cabendo, com isso, justificar qualquer desumanização durante o processo terapêutico, mas inferir que tais situações têm gerado tensões nos distintos espaços da prática em saúde bucal.

Segundo momento de encontro: linha de tensão do acolhimento no atendimento individual da equipe de saúde bucal

A Figura 3 demonstra a linha de tensão do acolhimento nos consultórios odontológicos, durante o atendimento individual (clínico) realizado entre a equipe de saúde bucal e o usuário, e de como o arsenal tecnológico é utilizado para responder aos problemas de saúde apresentados pela demanda.

Neste segundo momento das relações, Merhy 5 explica que é um espaço de decisão, em que os trabalhadores de saúde, de acordo com critérios variados, respondem às necessidades dos usuários. Trata-se de um espaço em que são definidas as estratégias interventoras, bem como se o atendimento pode ou não produzir saúde e, ademais, se o usuário pode ter sua demanda aceita ou recusada pelo serviço.

Mapeando as linhas de tensão que se processam nos encontros entre dentista/usuário e a tecnologia disponibilizada, tem-se o resultado do produto da intervenção que deve ser a prevenção, cura ou reabilitação da saúde ou, em contraposição, uma iatrogenia, manutenção ou agravamento da enfermidade. Após a escuta no acolhimento - recepção, abre-se um cardápio de serviços que a unidade de saúde da família dis- ponibiliza ao usuário, com um leque de opções bastante variável. Nesse sentido, a construção de novo modelo assistencial, cuja base está no espaço de trabalho, mostra os diversos interesses que se encontram e são pactuados entre si, o que pode vir a contribuir para uma assistência mais qualificada ao usuário, ou seja, significa produzir o cuidado de forma integral 23 .

No caso específico das práticas de saúde bucal, em alguns momentos as tecnologias duras estavam disponíveis à intervenção clínica, no entanto, o dentista realizava procedimentos rápidos, escolhendo sempre o mais simples de ser executado, negligenciando muitas vezes as normas de biossegurança e os critérios clínicos estruturados, comprometendo a qualidade do procedimento produzido. No entanto, a relação de encontro efetivou-se de forma leve e respeitosa, trazendo feixes de acolhida. Cada usuário, que entrava e saía do consultório, apresentava satisfação quanto ao tratamento relacional com o profissional, apesar de alguns demonstrarem insatisfação quanto ao procedimento realizado. Em outras palavras, o diálogo era efetivado, porém o produto (restauração, exodontia, dentre outros), que pressupõe garantia de resolubilidade e ganho de saúde, não se completava de forma satisfatória.

Observaram-se também situações criativas na realização de procedimentos clínicos possíveis, mesmo diante das limitações impostas. $\mathrm{O}$ uso do arsenal leve é o grande diferencial, aqui exemplificado. Um dos dentistas observados dava uma aula de como receber, ouvir e responsabilizar-se pelo sofrimento do outro. Simultaneamente, ainda com resolubilidade limitada, procurava com as ferramentas disponíveis contornar as dificuldades e desenvolver um processo de cuidado, centrado no usuário. "Ah, o doutor é o máximo. Ele conversa com a pessoa, brinca, se a pessoa tá com medo, só de tá conversando com ele acaba o medo e fica à vontade..." (Grupo III, entrevistado 13).

Durante o processo de observação, constatou-se que alguns profissionais detinham um aparato tecnológico disponível, no entanto, resolviam os problemas demandados pelos usuários de forma pontual e conflituosa, mantendo um afastamento entre eles; apesar de tecnicamente produzirem serviços com primazia, centralizavam a conduta terapêutica, restringindo o acolhimento. Um entrevistado relata: “... pelo profissional ser uma pessoa muito difícil de trabalhar, era muito complicado, a comunidade se queixava muito, (...) mas não da questão técnica" (Grupo II, entrevistado 7).

O processo de trabalho, desenvolvido pelos dentistas, pode ser descrito como tecnologica- 
mente duro (turbinas, resinas, limas endodônticas, exames laboratoriais), tendo como característica a dependência dos conhecimentos estruturados e elaborados previamente, mas que, por ser virtualmente presencial, complementase com a tecnologia leve, aquela dependente do encontro, da conversa. Dessa forma, contempla a dimensão subjetiva do ato terapêutico, circunscrita na produção do cuidado - o ato do atendimento clínico-odontológico.

Diante dessas considerações sobre a estrutura do trabalho em saúde bucal, resultado de um jogo de interesses muitas vezes não explicitados claramente, segundo as necessidades de cada um dos envolvidos no momento do atendimento, o usuário, o trabalhador e o próprio estabelecimento de saúde, o trabalhador é quem comanda a dinâmica desse trabalho, na medida em que toma decisões a partir de um cardápio de intervenções possíveis, elaborado por ele, na situação dada pelo espaço de produção das ações de saúde 18, no caso, em foco, da saúde bucal.

A característica que delineia as práticas em saúde bucal, por conseguinte, ao incorporarem o acolhimento, amplia e redimensiona a dependência por equipamentos e possibilita ao usuário novos trânsitos, novas combinatórias e diferentes respostas para demandas diversas. Em síntese, "todo mundo sabe alguma coisa e ninguém sabe tudo" 8 (p. 105).

A arte da conversa ${ }^{24}$ poderia ser possibilitada pelo redirecionamento do papel da clínica, enquanto instrumento de intervenção terapêutica, capaz de perceber e valorizar as necessidades explicitadas pelas pessoas que procuram um atendimento em uma unidade de saúde. O encontro entre um usuário, portador de uma dada necessidade de saúde, com um trabalhador, portador de um arsenal de saberes específicos e práticas, envolve situações não necessariamente convergentes. O que se procura obter, nesses encontros, é uma relação de compromisso que tenha como base a responsabilização e a confiança na intervenção, como uma possível solução para os problemas de quem solicita o atendimento em determinado serviço de saúde.

Terceiro momento de encontro: linha de tensão do acolhimento na conclusão ou não do processo terapêutico pela equipe de saúde bucal

Na Figura 4, encontra-se o pólo oposto, a última linha de tensão do acolhimento pela equipe de saúde bucal, que diz respeito à forma como o usuário conclui seu processo terapêutico, como é encaminhado a outros serviços e como é convidado a retornar a essa unidade.
As observações da prática convergem, no que diz respeito ao atendimento clínico conduzido de maneira pontual, algumas vezes rápido, centrado na queixa do usuário e limitado pelo número de vagas e equipamentos disponíveis no momento da consulta. As ações são centradas na intervenção do dentista, com falhas na biossegurança e nas próprias técnicas utilizadas para realização da intervenção clínica.

O processo terapêutico ocorre de distintas maneiras: atendimento nas urgências, nos casos de dor, traumatismo, infecções, hemorragias, dentre outros; encaminhamentos internos dos trabalhadores da própria unidade, solicitando o atendimento de saúde bucal; o agendamento de atendimento às crianças é realizado nas escolas, após triagem realizada pelo dentista ou pelo agente comunitário de saúde; agendamento nas microáreas, realizado pelo agente de saúde (idosos, gestantes, portadores de necessidades especiais e portadores de patologias crônicas); livre demanda, busca pelo serviço baseado na necessidade percebida pelo usuário, em dias programados na unidade; retornos programados: após a primeira consulta, o dentista faz um aprazamento para o retorno, baseado na necessidade ou risco do usuário, porém não existe garantia de conclusão do tratamento; encaminhamentos externos a outros serviços de saúde da rede, sem responsabilização da equipe para assegurar o atendimento.

Ressalta-se que o processo terapêutico organiza-se de forma tensa e conflitante, entre fazer ou não o tratamento completo, ou seja, concluir todas as necessidades que cada usuário apresenta, pelo menos, em relação aos procedimentos básicos ou resolver apenas os problemas demandados em cada consulta. No entanto, o tratamento que não se completa gera uma maior rotatividade de usuários que utilizam os serviços, criando um círculo vicioso, no qual a baixa resolubilidade acaba por gerar a permanência dos usuários por muito tempo no serviço, sem a garantia de que concluirão o tratamento ou se conseguirão resolver seus problemas.

Na tentativa de melhorar o acesso do usuário aos serviços de saúde bucal, o Ministério da Saúde, em 2004, publica um documento que define as Diretrizes da Política Nacional de Saúde Bucal 25. Tal documento revela que os serviços especializados em saúde bucal, na rede SUS, não chegam a 3,5\% do total dos procedimentos clínicos, não acompanhando a expansão da oferta que vem ocorrendo na rede básica, após implantação das equipes de saúde bucal no PSF.

Apesar desse cenário em relação ao acesso à saúde bucal, o Município de Chapecó, Santa Catarina, Brasil, apresenta experiência exitosa no 
âmbito das unidades de saúde, com tratamento completado 26. O usuário do sistema de saúde bucal recebe a primeira consulta e é aprazado para uma nova, a partir de suas necessidades, até que todos os procedimentos sejam concluídos em nível da atenção básica. Trata-se de uma possibilidade de romper com os tratamentos paliativos, originados apenas pela queixa do usuário, e caminhar rumo ao atendimento integral, com universalização do acesso, balizados pela eqüidade na assistência.

Para Merhy 5, conhecer a etapa final nos serviços de saúde é imprescindível para analisar o grau de resolubilidade e de comprometimento, em síntese, o coeficiente de saúde que é produzido em serviço. Apreender o nível de tensão, nesse momento, contribui para responder ao tipo de modelo de atenção: o que se produz, como é produzido, por quem e para quem.

Nesse sentido, o acolhimento envolve não somente trabalhador/usuário, mas também os contextos social, político, econômico e histórico configurados nas interfaces institucionais que permeiam a produção do trabalho em saúde. Com efeito, o dispositivo relacional do acolhimento deve fazer um reconhecimento das sinuosidades tensionais, nos vários momentos de encontro entre os trabalhadores de saúde e os usuários do serviço, procurando instituir novas comunicações que impliquem técnicas terapêuticas, centradas na pessoa que demanda por um cuidado. Seria vislumbrar o acolhimento como um dispositivo que oriente e homogenize as conversas nos espaços dos serviços de saúde, atravessado por um atendimento integral.

Dito de outra maneira, a equipe de saúde bucal, como parte do PSF, necessita de gestores comprometidos com a organização do sistema e engajados com a saúde coletiva; trabalhadores valorizados para desenvolver, plenamente, seu conhecimento específico, educados de forma contínua e permanente nos serviços e compromissados com a defesa da vida individual e coletiva; comunidade integrada nas decisões e no planejamento das propostas e ações de saúde; tudo isso, permitindo articulações com as proposições do SUS, num encontro concreto com a integralidade da atenção.

\section{Considerações finais}

A análise do acolhimento do usuário pelas equipes de saúde bucal, em unidades de saúde da família de uma realidade específica, revelou as dificuldades enfrentadas pela população na busca de garantir o acesso aos serviços de saúde bucal, que ainda apresenta relações tensas e confli- tantes, principalmente, pela baixa resolubilidade no atendimento às necessidades demandadas. Também mostra o percurso enfrentado por usuário e trabalhador na produção da atenção à saúde bucal, em diversos momentos: recepção, atendimento individual e a conclusão ou não do processo terapêutico (tratamento, retorno e encaminhamentos externos).

A partir deste estudo, coloca-se a possibilidade de repensar o processo de trabalho da equipe de saúde bucal, em especial, do dentista, para superar uma prática centrada na queixa e com baixa resolubilidade que tem gerado tensões e insatisfações, tanto para os trabalhadores da área, quanto para os usuários.

Acolher, em uma unidade de saúde, inicia-se com o diálogo no momento dos encontros, por meio do trabalho em equipe, configurando-se numa verdadeira teia comunicacional, tanto para os trabalhadores entre si, como para os trabalhadores e usuários. Sendo assim, cada encontro é um ponto de eminente tensão ou acolhimento, que poderá (ou não) produzir o cuidado. Finalmente, a confluência dos encontros de maneira acolhedora possibilita que o resultado do cuidado seja a conquista da saúde, na sua integralidade.

No entanto, sem desconsiderar a dívida social presente na atenção à saúde bucal no Brasil e, especificamente, em Alagoinhas, defende-se que ela não pode ser o ponto de justificativa para práticas pouco humanizadas ou não cuidadoras. Perceberam-se tensões e conflitos nos encontros entre os trabalhadores e usuários e, simultaneamente, a presença de novas possibilidades, novos caminhos. Ressalta-se que, "nem sempre é possível curar ou resolver uma necessidade apresentada, mas é sempre possivel cuidar, escutar e contribuir para amenizar o sofrimento do outro. Até porque, quem adoece a si, como um todo, ou seja, uma cárie, uma dor de dente, referente na boca, no corpo, na alma, na vida. Com alguém que sofre, sofrem os que o ama, então, o sofrimento é compartilhado, ainda que não dividido, por isso, é patente a necessidade de trabalhadores sensiveis, com uma nova ética na saúde" 27 (p. 60).

Por fim, as práticas curativas acumuladas podem ser resolvidas a partir da formulação de estratégias de organização local, a partir de rodas de negociações, criando-se, conjuntamente, critérios de atendimento na unidade de saúde da família, para as visitas domiciliares, para as atividades coletivas (promocionais e preventivas), com a conseqüente co-responsabilização e controle social. 


\section{Resumo}

O estudo discute as linhas de tensões do processo de acolhimento das equipes de saúde bucal, no Programa Saúde da Família, no Município de Alagoinhas, Bahia, Brasil, tomando como eixo orientador os fluxogramas analisadores do processo de trabalho em saúde. Tratase de uma pesquisa qualitativa, tendo como técnicas de coleta de dados: entrevista semi-estruturada e observação sistemática. Os sujeitos do estudo foram 17 pessoas: grupo I (cirurgiões-dentistas e auxiliares de consultórios dentários - 6); grupo II (outros trabalhadores de saúde - 6); grupo III (usuários - 5). Os resultados revelaram que o primeiro contato do usuário com a unidade de saúde da família é realizado na recepção, espaço privilegiado para utilização das tecnologias leves, sendo manifestado de forma tensa e conflitante, porém com potencialidade para construir alternativas de mudança. O processo terapêutico ocorre de distintas maneiras: consulta clínica, atendimento de urgência, retornos programados e encaminhamentos externos a outros serviços da rede. Contudo, as equipes de saúde bucal imprimem diferentes formas de acolhimento, ficando na dependência do compromisso e da singularidade dos sujeitos que atuam na prática.

Saúde Bucal; Acesso aos Serviços de Saúde; Avaliação de Serviços de Saúde

\section{Referências}

1. Cecílio LCO. As necessidades de saúde como conceito estruturante na luta pela integralidade e eqüidade na atenção em saúde. In: Pinheiro R, Mattos RA, organizadores. Os sentidos da integralidade na atenção e no cuidado à saúde. São Paulo: Editora Hucitec; 2001. p. 113-26.

2. Deleuze G, Guatarri F. Mil platôs: capitalismo e esquizofrenia. 3a Ed. v. 5. São Paulo: Editora 34; 2005.

3. Campos GWS. Considerações sobre a arte e a ciência da mudança: revolução das coisas e reforma das pessoas: o caso da saúde. In: Cecílio LCO, organizador. Inventando a mudança na saúde. São Paulo: Editora Hucitec; 1994. p. 29-88.

4. Campos GWS. Saúde paidéia. São Paulo: Editora Hucitec; 2003.

5. Merhy EE. Em busca do tempo: a micropolítica do trabalho vivo em saúde. In: Merhy EE, Onocko $\mathrm{R}$, organizadores. Agir em saúde um desafio para o público. São Paulo: Editora Hucitec; 1997. p. 71-112.

6. Mendes-Gonçalves RB. Tecnologia e organização social das práticas de saúde. São Paulo: Editora Hucitec; 1994

\section{Colaboradores}

A. M. Santos elaborou a pesquisa que deu origem ao artigo e participou da concepção e redação do artigo. M. M. A. Assis, A. A. A. O. Rodrigues, M. A. A. Nascimento, M. S. B. Jorge participaram da concepção do artigo e da análise nele contida.
7. Merhy EE. Saúde: a cartografia do trabalho vivo. São Paulo: Editora Hucitec; 2002.

8. Teixeira RR. O acolhimento num serviço entendido em rede de conversações. In: Pinheiro R, Mattos RA, organizadores. Construção da integralidade: cotidiano, saberes e práticas em saúde. Rio de Janeiro: Instituto de Medicina Social, Universidade do Estado do Rio de Janeiro/ABRASCO; 2003. p. 89-111.

9. Ministério da Saúde. Portaria n. 1.886/GM, de 18 de dezembro de 1997. Normas e diretrizes do Programa de Agentes Comunitários e do Programa de Saúde da Família. Diário Oficial da União 1997; 22 dez.

10. Brasil. Portaria n. 1.444 , de 28 de dezembro de 2000. Estabelece incentivo financeiro para a reorganização da atenção prestada nos municípios por meio do Programa de Saúde da Família. Diário Oficial da União 2000; $29 \mathrm{dez}$.

11. Brasil. Portaria n. 267/GM, de 6 de março de 2001. Reorganização das ações de saúde bucal na atenção básica. Portaria de Normas e diretrizes da saúde bucal. Diário Oficial da União 2001; 7 mar. 
12. Brasil. Portaria n. 673/GM, de 3 de junho de 2003. Atualiza e revê o incentivo financeiro às ações de saúde bucal, no âmbito do Programa de Saúde da Família, parte integrante do Piso de Atenção Básica - PAB. Diário Oficial da União 2003; 4 jun.

13. Ministério da Saúde. Revista CONASEMS: PSF sobe os morros do Rio. Brasília: Ministério da Saúde; 2004.

14. Minayo MCS. O desafio do conhecimento: pesquisa qualitativa em saúde. 6a Ed. São Paulo: Editora Hucitec; 1999.

15. Coordenação de Saúde Bucal, Secretaria Municipal de Saúde. Relatórios de saúde bucal. Alagoinhas: Secretaria Municipal de Saúde; 2003.

16. Comissão Nacional de Ética em Pesquisa, Ministério da Saúde. Normas para pesquisa envolvendo seres humanos. Brasília: Ministério da Saúde; 2000.

17. Merhy EE. Em busca da qualidade dos serviços de saúde: os serviços de porta aberta para a saúde e o modelo tecno-assistencial em defesa da vida (ou como aproveitar os ruídos do cotidiano dos serviços de saúde e colegiadamente reorganizar o processo de trabalho na busca da qualidade das ações de saúde). In: Cecílio LCO, organizador. Inventando a mudança na saúde. São Paulo: Editora Hucitec; 1994. p. 117-60.

18. Matumoto S. O acolhimento: um estudo sobre seus componentes e sua produção em uma unidade da rede básica de serviços de saúde [Dissertação de Mestrado]. Ribeirão Preto: Escola de Enfermagem, Universidade de São Paulo; 1998.

19. Cecílio LCO. Modelos tecno-assistenciais em saúde: da pirâmide ao círculo, uma possibilidade a ser explorada. Cad Saúde Pública 1997; 13:469-78.
20. Franco TB, Bueno WS, Merhy EE. O acolhimento e os processos de trabalho em saúde: o caso de Betim. In: Merhy EE, Magalhães Jr. HM, Rímoli J, Franco TB, Bueno WS, organizadores. O trabalho em saúde: olhando e experenciando o SUS no cotidiano. São Paulo: Editora Hucitec; 2003. p. 37-54.

21. Schimith MD, Lima MADS. Acolhimento e vínculo em uma equipe do Programa Saúde da Família. Cad Saúde Pública 2004; 20:1487-94.

22. Manfredini MA. PSF: promovendo saúde bucal. Revista Brasileira de Saúde da Família 2004; 7: 62-71.

23. Franco TB, Peres MAA, Foschiera MMP, Panizzi M, organizadores. Acolher Chapecó: uma experiência de mudança do modelo assistencial, com base no processo de trabalho. São Paulo: Editora Hucitec; 2004.

24. Shapiro J, Ross V. Apllications of narrative theory and therapy to the practice of family medicine. Fam Med 2002; 34:96-100.

25. Conselho Nacional de Secretários de Saúde, Ministério da Saúde. Diretrizes da política nacional de saúde bucal. Brasília: Ministério da Saúde; 2004.

26. Panizzi M, Peres MAA, Moschetta JDF. Saúde bucal: em busca da universalidade, da integralidade $\mathrm{e}$ da eqüidade. In: Franco TB, Peres MAA, Foschiera MMP, Panizzi M, organizadores. Acolher Chapecó: uma experiência de mudança do modelo assistencial, com base no processo de trabalho. São Paulo: Editora Hucitec; 2004. p. 145-79.

27. Santos AM, Assis MMA. Da fragmentação à integralidade: construindo e (des)construindo a saúde bucal no Programa de Saúde da Família (PSF) de Alagoinhas, BA. Ciênc Saúde Coletiva 2006; 11: 53-61.

Recebido em 27/Set/2005

Versão final reapresentada em 14/Mar/06

Aprovado em 02/Mai/2006 